\title{
Ensuring breastfeeding-supportive legislation
}

\author{
Shetal Shah', Boriana Parvez ${ }^{1}$ and Heather L. Brumberg ${ }^{1,2}$
}

$S^{t}$

teady increases in national breastfeeding rates approaching the national Healthy People 2020 benchmarks have been observed over time (1). Two articles in this issue add to the well-known benefits of breastfeeding $(2,3)$. Interestingly, there appears to be substantial overlap between states whose breastfeeding rates are lower than Healthy People 2020 goals with those who chose not to accept the federally-funded Medicaid Expansion as part of the Affordable Care Act (ACA). Overall the total number of children benefiting from breastfeeding in these regions remains suboptimal (4)

The ACA provides several provisions aimed at supporting breastfeeding mothers. These include mandatory break time and dedicated space for mothers to express breastmilk, coverage for breastfeeding supplies (including pumps), and lactation support $(5,6)$. These policies, which affect $\sim 19$ million women, have led to increased worksite compliance for private breastfeeding space and are associated with a $2.5 \%$ increase in initiation of breastfeeding (an estimated 47,000 more women) (7-9).

Breastmilk is the premium nutritional source for infants and is associated with reduced mortality, and decreased rates of infections, allergies, asthma, Type 2 diabetes, and obesity (10). In this issue of Pediatric Research, Julvez et al. report on lower rates of autistic traits and improved cognitive function in breastfed infants in early childhood (2). Gridneva and colleagues, also in this issue, reinforce the beneficial effects of breastfeeding on adiposity, a risk factor for later obesity (3).

To continue to sustain increases in breastfeeding rates, greater societal understanding that breastfeeding rates profit from a network of social policies is needed (11). Given the influence of such measures on breastfeeding rates, the health improvements infants receive from breastfeeding are thus partially socially-determined. Physicians should advocate for standard regulations which assist breastfeeding mothers including:

\section{SUPPORTING FEDERAL, UNIVERSAL PAID FAMILY LEAVE FOR AT LEAST 14 WK TO HELP SUSTAIN BREASTFEEDING AFTER HOSPITAL INITIATION}

Paid maternity leave is strongly associated with persistence of breastfeeding $(11,12)$. No national regulations exist in the United States for paid family leave. Five states have enacted paid family leave ranging from 4-12 wk of time off at roughly half to two thirds of pay (13). Exclusive of these states, voluntary paid leave is available to $\sim 10 \%$ of American employees, but the durations are shorter than those of other economicallysimilar nations who offer between $14-52$ wk $(13,14)$. Longer employment leaves are associated with improved breastfeeding outcomes $(11,13)$. Of note, paid family leave is only one of a constellation of social policies such as on-site childcare, flexible work scheduling, access to healthcare, equal pay, and paternity leave which positively influence sustained breastfeeding (15-17).

\section{MAINTAINING EXPANDED INSURANCE COVERAGE CREATED BY THE ACA SO ELIGIBLE MOTHERS CONTINUE TO OBTAIN BREASTFEEDING BENEFITS SUCH AS LACTATION CONSULTATION, BREAST PUMPS, AND SUPPLIES}

Through provisions such as the Medicaid Expansion, the ACA has provided coverage for an estimated 11.6 million women of childbearing age (18). Recent threats to repeal ACA would endanger the insurance mandates related to breastfeeding and may imperil the gains achieved. Other aspects of the ACA, if modified, may impact national breastfeeding rates. The ACA penalizes hospitals which under-perform in certain quality metrics such as $30-\mathrm{d}$ readmission or central line associated blood stream infections resulting in reductions of preventable conditions as well as cost $(19,20)$. Formula feeding in the setting of a mother who could breastfeed should be considered among these preventable conditions and included in ACA sanctions $(18,19)$.

\section{PROVIDING ADEQUATE FINANCING FOR THE SPECIAL SUPPLEMENTAL NUTRITION PROGRAM FOR WOMEN, INFANTS, AND CHILDREN (WIC) PROGRAM WHICH SUPPORTS THE NUTRITIONAL NEEDS OF BREASTFEEDING MOTHERS AND ENCOURAGES SUSTAINING BREASTFEEDING OF INFANTS}

WIC provides targeted nutritional support to infants whose families earn up to $185 \%$ of the Federal Poverty Level. In 2012, almost half of all infants born in the United States participated in the program (21). Reauthorization of WIC incentivizes breastfeeding by providing performance bonuses for states with improved and sustainably-high breastfeeding rates $(21,22)$. Currently, WIC also includes stipulations for breastfeeding

'Division of Neonatology, New York Medical College, Valhalla, New York; ${ }^{2}$ Liquid Gold Premie Milk Bank, Maria Fareri Children's Hospital, Valhalla, New York. Correspondence: Shetal Shah (shetaldoc@hotmail.com)

Received 27 December 2016; accepted 27 December 2016; advance online publication 15 February 2017. doi:10.1038/pr.2016.277 


\section{Ensuring breastfeeding-supportive legislation}

counseling (23). However WIC remains a discretionary program and is vulnerable to funding changes during budgetary negotiations, including assignment of a "block grant" allocation which functionally decreases funding streams.

\section{ELIMINATING ALLOCATION OF BLOCK GRANTS TO STATES DURING THE FEDERAL APPROPRIATIONS PROCESS TO ENSURE THESE PROGRAMS ARE FUNDED TO A LEVEL APPROPRIATE TO PROVIDE BENEFITS TO ALL ELIGIBLE MOTHERS}

"Block Grant" proposals limit spending to flat amount rather than funding per eligible enrollee and are a feature of House of Representatives' Speaker Paul Ryan's healthcare plan (24). As a result, state expenses increase by addressing fiduciary gaps between the set dollar amount and expenses for new registrants, resulting in a limitation of Medicaid-covered services, decreased payments and disincentivized enrollment in social programs. For new mothers, this has the potential to limit the number of mothers receiving breastfeeding support through Medicaid and WIC $(23,25)$. Use of Block Grants during the upcoming federal appropriations process is estimated to result in 14 million people denied access to Medicaid (and its breastfeeding-friendly insurance coverage) over the next decade (25-27).

Sustainable improvement in the number of breastfed infants requires both forceful defensive advocacy for gains already realized, and a fundamental shift in societal attitudes toward supporting mothers at the federal, state, and employer level. In their role as child health experts, pediatricians can ensure federal policies exert positive influences on newborn health; ensuring programs linked to breastfeeding promotion are substantive and remain financially viable.

\section{REFERENCES}

1. Office of Disease Prevention and Health Promotion. Healthy People.gov, 2016. https://www.healthypeople.gov/2020/topics-objectives/topic/Maternal-Infant-and-Child-Health/objectives\#4859. Accessed 29 November 2016.

2. Julvez J, Boucher O, Guxens M, Arranz E, Ibarluzea J, Sanchez de Miguel M et al. Association between breastfeeding duration and cognitive development, autistic trais and ADHD symptoms: a multicenter study in Spain. Ped Res 2017;81:434-442.

3. Gridneva Z, Hepworth A, WardL,LaiCT,HartmannP, Geddes D. Determinants of body composition in breastfed infants using bioimpedance spectroscopy and ultrasound skinfolds - methods comparison. Ped Res 2017;81:423-433.

4. Centers for Disease Control, National Center for Chronic Disease Prevention and Health Promotion, Division of Nutrition, Physical Activity, and Obesity. Breastfeeding Report Card: Progressing Toward National Breastfeeding Goals United States, 2016.

5. Hawkins SS, Dow-Fleisner S, Noble A. Breastfeeding and the Affordable Care Act. Pediatr Clin North Am 2015;62:1071-91.

6. American Academy of Pediatrics, Federal Support for Breastfeeding. https://www2.aap.org/breastfeeding/files/pdf/FederalSupportforBreastfeedingResource.pdf. Accessed 29 November 2016.

7. Drago R, Hayes J, Yi Y. Better Health for Mothers and Children: Breastfeeding Accommodations under the Affordable Care Act. Institute for Women's Policy Research, 2010.
8. Department of Health and Human Services, Assistant Secretary for Planning and Evaluation. Health Insurance Coverage and The Affordable Care Act, Sept 22, 2015. https://aspe.hhs.gov/basic-report/health-insurancecoverage-and-affordable-care-act-september-2015. Accessed 29 November 2016.

9. Abdulloeva S, Eyler AA. Policies on worksite lactation support within states and organizations. J Womens Health 2013;22:769-74.

10. Horta BL, Loret de Mola C, Victora CG. Long-term consequences of breastfeeding on cholesterol, obesity, systolic blood pressure, and type 2 diabetes: a systematic review and meta-analysis. Acta Paediatr 2015;104:30-7.

11. Borrell C, Palència L, Muntaner C, Urquía M, Malmusi D, O’Campo P. Influence of macrosocial policies on women's health and gender inequalities in health. Epidemiol Rev 2014;36:31-48.

12. Baker M, Milligan K. Maternal employment, breastfeeding, and health: evidence from maternity leave mandates. J Health Econ 2008;27: 871-87.

13. Burtle A, Bezruchka S. Population health and paid parental leave: what the United States can learn from two decades of research. Healthcare 2016; 4:30.

14. Van Giezen, R.W. Paid leave in private industry over the past 20 years; Contract No. 18; Bureau of Labor Statistics: Washington, DC, USA, 2013. http://www.bls.gov/opub/btn/volume-2/paid-leave-in-private-industryover-the-past-20-years.htm. Accessed 29 November 2016.

15. Pascall G, Lewis J. Emerging gender regimes and policies for gender equality in a wider Europe. J Soc Policy. 2004;33:373-94.

16. Yngve A, Sjöström M. Breastfeeding determinants and a suggested framework for action in Europe. Public Health Nutr 2001;4(2B):729-39.

17. Grande D, Srinivas SK; Society for Maternal-Fetal Medicine Health Care Policy Committee. Leveraging the Affordable Care Act to improve the health of mothers and newborns. Obstet Gynecol 2013;121:1300-4.

18. Shah SI, Brumberg HL. Predictions of the affordable care act's impact on neonatal practice. J Perinatol 2016;36:586-92.

19. Shah SI, Brumberg HL, Bearer CF. Toward development of evidencedbased quality parameters: What gets counted and who gets paid? Pediatr Res 2016;80:170-1.

20. Blumenthal D, Abrams M, Nuzum R. The Affordable Care Act at 5 years. $N$ Engl J Med 2015;372:2451-8.

21. Martinez-Schiferl M. WIC Participants and Their Growing Need for Coverage. Urban Institute, Income and Benefits Policy Center, April 2012 http:// www.urban.org/sites/default/files/alfresco/publication-pdfs/412549-WICParticipants-and-Their-Growing-Need-for-Coverage.PDF. Accessed 29 November 2016.

22. Ryan AS, Zhou W. Low breastfeeding rates persist among the Special Supplemental Nutrition Program for women, infants, and children participants, 1978-2003. Pediatrics 2006;117:1136-46.

23. American Academy of Pediatrics Blueprint for Children: How the Next President can Build a Foundation for a Health Future 2016. https://www. aap.org/en-us/Documents/BluePrintForChildren.pdf. Accessed 1 November 2016.

24. Ryan P. A Better Way: Our Vision for a Confident America 2016. http:// abetterway.speaker.gov/_assets/pdf/ABetterWay-Poverty-PolicyPaper.pdf. Accessed 27 November 2016.

25. Rosenbaum S, Schmucker S, Rothenberg S, Gunsalus R. What Would Block Grants or Limits on Per Capita Spending Mean for Medicaid? The Commonwealth Fund, November. 2016 http://www.commonwealthfund. org/publications/issue-briefs/2016/nov/medicaid-block-grants. Accessed 26 November 2016.

26. Park E. Medicaid Block Grant Would Add Millions to Uninsured and Underinsured Center on Budget and Policy Priorities. 2016. http://www. cbpp.org/blog/medicaidblockgrantwouldaddmillionstouninsuredandunderinsured. Accessed 29 November 2016.

27. Lambrew JM. Making Medicaid a block grant program: an analysis of the implications of past proposals. Milbank Q 2005;83:41-63. 